\title{
Nitretação e deposição por plasma em ferramentas de aços AISI M2 e D2 utilizadas na conformação e estampagem de pregos: um estudo de viabilidade
}

\author{
Plasma nitriding and deposition in AISI M2 and \\ D2 steel tools used in nail forming and stamping: \\ a viability study
}

\author{
Edno da Silveira Costa ${ }^{1}$, Rômulo Ribeiro Magalhães de Sousa ${ }^{1}$, \\ Renan Matos Monção ${ }^{1}$, Maxwell Santana Libório ${ }^{2}$, Thércio Henrique de Carvalho Costa ${ }^{2}$
}

\footnotetext{
${ }^{1}$ Laboratório de Processamento de Materiais por Plasma - Labplasma, PPGCM/UFPI, Campus Universitário Ministro Petrônio Portella, s/n Bairro - Ininga, Teresina, PI, Brasil.

${ }^{2}$ Laboratório de Processamento de Materiais por Plasma - LabPlasma, Departamento de Engenharia Mecânica, PPGECM / UFRN, Av. Sen. Salgado Filho, 3000 - Candelária, Natal, RN, Brasil.

e-mail: ednosilveira15@gmail.com, romulorms@gmail.com, renanmatos2010@ hotmail.com,

maxwellsantana@ect.ufrn.br, thercioc@gmail.com
}

\section{RESUMO}

A crescente necessidade de aumentar a produtividade do setor industrial, impulsiona o desenvolvimento de novos aços e novos tratamentos que possam melhorar o desempenho e a vida útil de ferramentas de corte, conformação e estampagem. Tratamentos de superfície assistidos por plasma destacam-se nesse contexto. Trabalhos anteriores têm demonstrado que esses revestimentos são eficientes no aumento da dureza, na resistência ao desgaste e na resistência a corrosão de diversos tipos de aços. Nesse sentido, amostras e ferramentas de aços AISI M2 e D2 termicamente tratadas foram submetidas aos processos de nitretação a plasma convencional, em gaiola catódica e tratamento duplex com o objetivo de avaliar o efeito desses tratamentos em ferramentas de conformação buscando a viabilidade da aplicação do método no setor industrial com a redução do custo de fabricação na conformação e estampagem de pregos. Ensaios de microdureza Vickers, análise por MEV e Difração de Raios-X (DRX) possibilitaram identificar propriedades mecânicas, camada de compostos e as fases presentes, respectivamente. $\mathrm{O}$ desempenho das ferramentas baseou-se na quantidade de pregos produzida em kg. O custo produtivo foi determinado em função da produtividade, do preço de aquisição da ferramenta e do preço da nitretação. $\mathrm{O}$ uso da nitretação a plasma se mostrou viável para os dois aços, destacando-se o fato de que as ferramentas de aço D2 nitretadas a $480^{\circ} \mathrm{C}$ por 3 horas, obtiveram os maiores ganhos de produtividade em relação a ferramenta não nitretada. A aplicação da nitretação convencional na ferramenta de aço $\mathrm{M} 2$ a $480^{\circ} \mathrm{C}$ por 4 horas possibilitou a redução de seu custo em $26 \%$ e redução de $3,5 \%$ sobre o custo total de produção de pregos, obtendo o melhor custo-benefício.

Palavras-chave: Nitretação a plasma, gaiola Catódica, duplex, aços AISI M2 e D2.

\section{ABSTRACT}

The growing need to increase the productivity of the industrial sector, drives the development of new steels and new treatments that can improve the performance and useful life of cutting, forming and stamping tools. Plasma-assisted surface treatments stand out in this context. Previous research has shown that these coatings are efficient in increasing hardness, wear resistance and corrosion resistance of different types of steels. In this sense, samples and tools from AISI M2 and D2 heat-treated steels were subjected to conventional plasma nitriding processes, in cathodic cage and duplex treatment in order to evaluate the effect of these treatments on forming tools seeking the viability of applying the method in the industrial sector with the reduction of the manufacturing cost in the conformation and stamping of nails. Vickers microhardness tests, SEM analysis 
and X-Ray Diffraction (XRD) made it possible to identify mechanical properties, layer of compounds and the phases present, respectively. The performance of the tools was based on the volume of nails produced in $\mathrm{kg}$. The productive cost was determined in function of productivity, the purchase price of the tool and the nitriding price. The use of plasma nitriding proved to be feasible for both steels, highlighting the fact that the D2 steel tools nitrided at $480^{\circ} \mathrm{C}$ for 3 hours, obtained the greatest productivity gains in relation to non-nitrided tool. The application of conventional nitriding in the steel tool $\mathrm{M} 2$ at $480^{\circ} \mathrm{C}$ for 4 hours made it possible to reduce its cost by $26 \%$ and reduce by $3.5 \%$ the total cost of producing nails, obtaining the best cost-benefit ratio.

Keywords: Plasma Nitriding, cathodic cage, duplex, AISI M2 and D2 steels.

\section{INTRODUÇÃO}

Nas operações de conformação e corte, as solicitações mecânicas são elevadas e por isso exigem ferramentas fabricadas a partir de aços com propriedades especiais de resistência e tenacidade. Além disso, é de extrema importância se considerar as solicitações tribológicas a que a superfície de trabalho é solicitada. As superfícies dessas ferramentas necessitam de propriedades que minimizem os efeitos do desgaste [1].

São conhecidas mais de uma centena de aços ferramenta, porém os aços para ferramentas de trabalho a frio são a categoria mais importante, pois são usados para muitos tipos de ferramentas e matrizes e outras aplicações onde são necessárias alta resistência ao desgaste e baixo custo [2], entre os quais, são preferidos na indústria metal-mecânica, aqueles que possuem suas propriedades e desempenhos conceituado ao longo do tempo, como por exemplo, os aços AISI D2 e AISI M2 [3].

Os principais objetivos da indústria de transformação de produtos siderúrgicos são minimizar custos, melhorar a qualidade do produto, aperfeiçoar o processo produtivo e aumentar a produtividade [4]. Com base na necessidade da indústria, a engenharia de superfície se destaca nesse cenário com a aplicação de filmes superficiais que permitem obter melhores propriedades em materiais metálicos [5], destacando-se a nitretação que compreende diversas técnicas de aplicação de filmes nas quais se introduz nitrogênio na superfície de um material. [6].

Entre todas as tecnologias de engenharia de superfície que são bem comprovadas cientificamente e tecnicamente para projetar a superfície de vários componentes de engenharia, a nitretação está entre as primeiras a serem aceitas e amplamente utilizadas pela indústria [7]. A nitretação por plasma tem recebido grande atenção por ser um processo que assegura baixa distorção nos componentes nitretados e não polui o meio ambiente, tratando-se de um processo termoquímico para melhorar as propriedades da superfície, como resistência ao desgaste, resistência à corrosão e resistência à fadiga de vários aços de engenharia [8].

O trabalho de Depianti, M. et al. (2014), demonstrou que a nitretação a plasma com $20 \% \mathrm{~N} 2$ a $470^{\circ} \mathrm{C}$ possibilitou o aumento da dureza superficial e da resistência ao desgaste micro-abrasivo do aço ferramenta AISI D2. A melhor resistência ao desgaste é oferecida por camadas nitretadas produzidas sem uma camada de compostos e nitretos em contorno de grão [9]. Segundo Pessin, M. A. et al. (2000), a nitretação a plasma melhora a resistência ao desgaste do aço-ferramenta AISI M2, porém deve-se manter o controle adequado dos parâmetros de nitretação, como por exemplo, pressão e temperatura do gás, pois esses parâmetros desempenham um papel importante na formação da espessura da camada compostos, estrutura e resistência ao desgaste [10].

A nitretação a plasma em gaiola catódica, evolução da técnica de nitretação a plasma convencional, é um método que vem sendo utilizado para o aprimoramento de características superficiais de vários materiais [11]. Os principais benefícios consistem em minimizar as limitações ou defeitos provenientes da nitretação convencional como efeito de borda, abertura de arcos e efeito de cátodo oco em amostras com geometria complexa $[12,13]$. Nessa técnica, as amostras são mantidas no interior de uma gaiola e sobre uma placa isolante. Esse mecanismo é baseado em pulverização catódica (sputtering) e redeposição do metal da gaiola [11].

Buscando identificar o melhor tratamento para o aço AISI D2, Sousa et al. (2009) concluiu que as melhores condições para a nitretação em gaiola catódica desse aço foram a $480{ }^{\circ} \mathrm{C}$, por 3 horas [14]. Araújo (2015) realizou nitretação a plasma convencional em ferramentas de corte e Abreu (2018) nitretou punções de aço M2 utilizando as técnicas de gaiola catódica e nitretação convencional. Ambos encontraram excelentes resultados utilizando temperaturas entre 450 e $500^{\mathrm{a}} \mathrm{C}$ por 4 horas $[15,3]$. Com base nessas pesquisas foram propostos os parâmetros de nitretação para cada tipo de aço utilizado.

Outro tratamento com excelentes resultados na aplicação em ferramentas é o tratamento duplex que consiste em associar um tratamento preliminar de nitretação a plasma e a deposição física de vapor - PVD, produzindo um substrato de aço nitretado e um revestimento PVD rígido de alta dureza, resistência ao des- 
gaste e à fadiga, aliado a capacidade do substrato nitretado em suportar ciclos de carregamentos [16]. Além disso, exibem, estabilidade térmica e baixo atrito. O nitreto de titânio (TiN) é um dos revestimentos de PVD mais utilizados. O PVD tem a vantagem de ser realizado em baixa temperatura de processamento quando comparado ao CVD e não alterar significativamente a dimensão do substrato [17].

Franco Júnior, Pinedo e Tschiptschin (2009) realizaram tratamento duplex em um aço H13 e após testes de desgaste microabrasivo, concluíram que o uso de longos tempos de nitretação não contribui para aumentar a resistência ao desgaste das camadas nitretadas e, consequentemente, dos respectivos revestimentos dúplex [18].

Neste trabalho, ferramenta e amostras de aço AISI D2 e M2 temperadas e revenidas foram submetidas aos tratamentos de nitretação convencional a plasma e com o uso de gaiola catódica a $480^{\circ} \mathrm{C}$, por 3 e 4 h respectivamente. A deposição de TiN sobre amostras previamente nitretadas em gaiola catódica, foi efetuada na temperatura de $420^{\circ} \mathrm{C}$ por $3 \mathrm{~h}$, caracterizando o tratamento duplex.

Apesar de existirem diversos trabalhos com deposição e nitretação em amostras de aços ferramenta, trabalhos científicos com a aplicação dessas técnicas diretamente na indústria ainda são poucos explorados. O objetivo do trabalho é avaliar o efeito desses tratamentos no desempenho de ferramentas de conformação e estampagem de pregos, buscando o aumento da vida útil das ferramentas e a redução do custo de fabricação com a identificação do melhor custo-benefício entre os aços e tratamentos testados no sentido de demonstrar a viabilidade da aplicação do método no setor industrial

\section{MATERIAIS E MÉTODOS}

Na composição do estudo foi utilizado os aços ferramenta AISI D2 e AISI M2 (aço rápido), com composição química nominal indicada na Tabela 1 . Os aços utilizados foram adquiridos na VILLARES METALS, porém as amostras/ferramentas usinadas e termicamente tratadas foram fornecidas pela empresa THADIG Indústria Mecânica. $\mathrm{O}$ revenimento do aço $\mathrm{M} 2$ foi realizado a $550^{\circ} \mathrm{C}$, com dureza final de $984 \mathrm{HV}$, já o aço D2 foi revenido a $500^{\circ} \mathrm{C}$ e obteve dureza final de $661 \mathrm{HV}$.

Tabela 1: Composição química nominal dos aços utilizados no estudo ( \% massa).

\begin{tabular}{l|l|l|l|l|l|l|l}
\hline ELEMENTO & C & MN & CR & MO & W & V & OUTROS \\
\hline \% Massa M2 & 0,90 & 0,30 & 4,20 & 4,90 & 6,20 & 1,80 & - \\
\hline \% Massa D2 & 1,50 & 0,35 & 12,0 & 0,78 & - & 0,80 & - \\
\hline
\end{tabular}

As amostras utilizadas para os tratamentos foram obtidas a partir de barras de $22 \mathrm{~mm}$ de diâmetro e 50 $\mathrm{mm}$ de comprimento. As barras foram cortadas, com cortadeira constantemente refrigerada, em 4 discos de aproximadamente $6 \mathrm{~mm}$ de espessura e posteriormente divididas ao meio, compondo um conjunto de 4 amostras para cada tipo de aço.

As amostras foram lixadas e polidas com a finalidade de remover todas as imperfeições do processo de corte. Utilizou-se lixas d'agua abrasivas com granulometria de 100, 220, 400, 600 e 1200 mesh para retirada das imperfeiçoes. O polimento foi realizado utilizando alumina em suspensão $(1 \mu \mathrm{m}) \mathrm{com}$ o auxílio de uma máquina politriz. Após o polimento, as amostras foram lavadas com água e acetona, secas e armazenadas com uma proteção de vaselina liquida para evitar a oxidação.

As ferramentas de conformação, termicamente tratadas nas mesmas condições de suas respetivas amostras, foram disponibilizadas pela empresa Ferronorte Industrial. O custo de aquisição das ferramentas utilizadas no estudo pode ser visto na Tabela 2.

Tabela 2: Custos das ferramentas adquiridas pela Ferronorte Industrial.

\begin{tabular}{c|c|c}
\hline AÇO & TRATAMENTO TÉRMICO & PREÇO (R\$) \\
\hline M2 & Tempera Sub-Zero & 295,00 \\
\hline D2 & Têmpera convencional & 220,00 \\
\hline
\end{tabular}

Essas ferramentas apresentam frisos na superfície de trabalho e, portanto, foram lixadas com lixas de granulometrias 1200 mesh para melhor aderência do filme. Posteriormente foram lavadas e secadas com secador convencional. As ferramentas e amostras são conforme a Figura 1. 

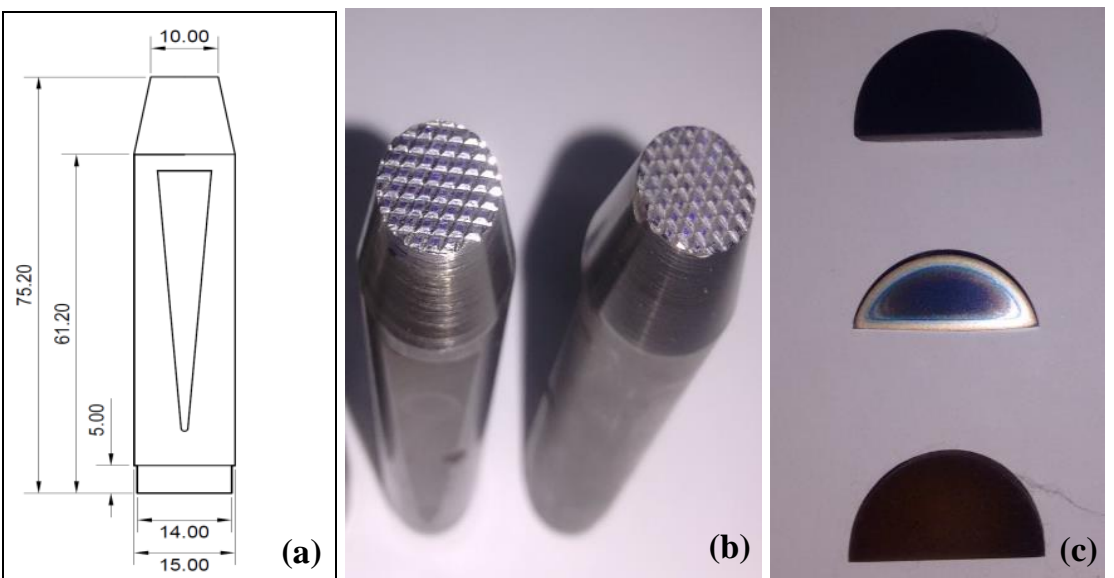

Figura 1: Ferramenta de estampagem e amostras: (a) desenho técnico da ferramenta e suas principais dimensões (b) imagem de ferramentas com detalhe da face de trabalho e (c) amostras após tratamentos de nitretação e deposição.

Nos processos com a utilização de gaiola catódica, foi necessário realizar limpeza previa da gaiola. Inicialmente a gaiola foi lixada com lixa d'água de 220 mesh para retirar os resíduos provenientes de tratamentos anteriores. A gaiola foi então lavada com água e sabão e seca com secador convencional de ar quente. Posteriormente uma limpeza final para retirada dos resíduos foi realizada com acetona em um aparelho de ultrassom por um período de 10 min e secada antes da utilização. Todas as gaiolas utilizadas seguiram o mesmo procedimento.

Nos procedimentos foram utilizadas quatro gaiolas catódicas; duas confeccionadas em aço inoxidável austeniticos 304 e duas gaiolas de titânio. As amostras são colocadas dentro da gaiola e posicionadas no centro sobre um disco isolante de alumina com $32 \mathrm{~mm}$ de diâmetro e $3 \mathrm{~mm}$ de espessura.

\subsection{Nitretação e deposição}

A nitretação e deposição foram realizadas num equipamento constituído de vários componentes dentre os quais pode-se destacar um reator confeccionado em aço inoxidável austenítico, com $300 \mathrm{~mm}$ de diâmetro e $500 \mathrm{~mm}$ de profundidade, uma bomba de vácuo modelo E2M5 com uma capacidade máxima de 0,2 mbar, uma fonte de tenção com saída D.C e uma voltagem máxima de $1200 \mathrm{~V}$ de corrente capaz de fornecer energia suficiente para que a amostra seja aquecida a uma temperatura de aproximadamente $600^{\circ} \mathrm{C}$ e um sistema de controle de fluxo de gases com capacidade de controle de até $200 \mathrm{sccm}$.

A primeira etapa de nitretação é a limpeza por plasma ou pré-sputtering que objetiva a remoção de óxidos e outros contaminantes da superfície da amostra em teste, bem como ativar a superfície para facilitar a difusão. O pré-sputtering foi realizado a $350^{\circ} \mathrm{C}$, em uma atmosfera gasosa de $50 \% \mathrm{H} 2$ e $50 \%$ Ar para os tratamentos com gaiola e duplex, com fluxo de $15 \mathrm{Sccm}$. Durante a nitretação convencional utilizou-se 100\% H2 e fluxo de $20 \mathrm{sccm}$. A pressão foi entre 0,8 e 1,3 mbar por um período de $1 \mathrm{~h}$ para todos os tratamentos. Durante a fase de sputtering, a corrente foi então aumentada até atingir a temperatura desejada e mantida estável pelo tempo determinado para cada tratamento. Em seguida o reator foi desligado e as amostras resfriadas no interior da câmara de vácuo até atingirem a temperatura ambiente. Os parâmetros de nitretação e deposição são mostrados na Tabela 3 .

Tabela 3: Parâmetros utilizados para os tratamentos.

\begin{tabular}{c|c|c|c|c|c|c}
\hline CódIGO & AÇO AISI & TRATAMENTO & $\begin{array}{c}\text { ATMOSFERA } \\
\text { (SCCM) }\end{array}$ & $\begin{array}{c}\text { PRESSÃO } \\
\text { (MBAR) }\end{array}$ & $\begin{array}{c}\text { TEMPERATURA } \\
\text { (으) }\end{array}$ & TEMPO (H) \\
\hline M2C & M2 & Convencional & $24 \mathrm{H}_{2} / 6 \mathrm{~N}_{2}$ & 3,0 & 480 & 4 \\
\hline D2C & D2 & Convencional & $24 \mathrm{H}_{2} / 6 \mathrm{~N}_{2}$ & 3,0 & 480 & 3 \\
\hline M2G & M2 & Gaiola & $24 \mathrm{~N}_{2} / 6 \mathrm{H}_{2}$ & 3,0 & 480 & 4 \\
\hline D2G & D2 & Gaiola & $24 \mathrm{~N}_{2} / 6 \mathrm{H}_{2}$ & 3,0 & 480 & 3 \\
\hline M2D & M2 & Duplex & $24 \mathrm{H} 2 / 8 \mathrm{~N}_{2}$ & 1,5 & 420 & 3 \\
\hline D2D & D2 & Duplex & $24 \mathrm{H}_{2} / 8 \mathrm{~N}_{2}$ & 1,5 & 420 & 3 \\
\hline
\end{tabular}


Na deposição realizada com gaiola de titânio, utilizou-se uma amostra e uma ferramenta de cada tipo de aço. As amostras/ferramentas de códigos M2D e D2D foram previamente tratadas com nitretação em gaiola catódica de aço inoxidável conforme parâmetros utilizados para as amostras M2G e D2G e posteriormente feita deposição utilizando gaiola de titânio, permitindo a obtenção de um tratamento duplex.

\subsection{Caracterização das amostras}

A determinação das fases presentes foi feita por análise de difração de Raios-X, em um difratômetro da mar-

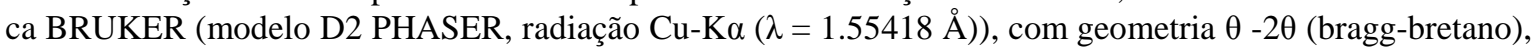
operando em com tensão de $30,0 \mathrm{KV}$, corrente: $10,0 \mathrm{~mA}$ e ângulo de varredura (20): de $20^{\circ}$ a $80^{\circ}$.

Os ensaios de microdureza das amostras com e sem nitretação foram feitos utilizando o padrão Vickers (HV), em um microdurômetro de marca INSIZE modelo ISH-TDV 1000A-B. Devido a fina camada depositada, a carga utilizada foi de 50 gf para evitar deformações nas impressões feitas pelo indentador, conforme a norma ASTM 1327-08 [19]. Na avaliação da camada superficial, realizaram-se cinco indentações em cada amostra. Para obtenção do perfil utilizou a medição da superfície e as demais identações foram realizadas a $20,30,60,90,120,150$ e 220,330 e $500 \mu \mathrm{m}$.

A microestrutura das amostras e a espessura da camada de compostos formada durante o processo de nitretação e deposição a plasma foi avaliada com utilização do microscópio eletrônico de varredura (MEV) da marca Hitachi, modelo TM3000, utilizando aumentos de 100 a 2000 vezes.

\subsection{Desempenho das ferramentas}

As ferramentas de estampagens foram testadas em uma máquina de fabricação de prego Vitari modelo V14$\mathrm{R}$ com capacidade produtiva de 720 pegos por minuto (aproximadamente $55 \mathrm{Kg} / \mathrm{h}$ ). A figura 2 mostra a máquina utilizada para realização dos testes.

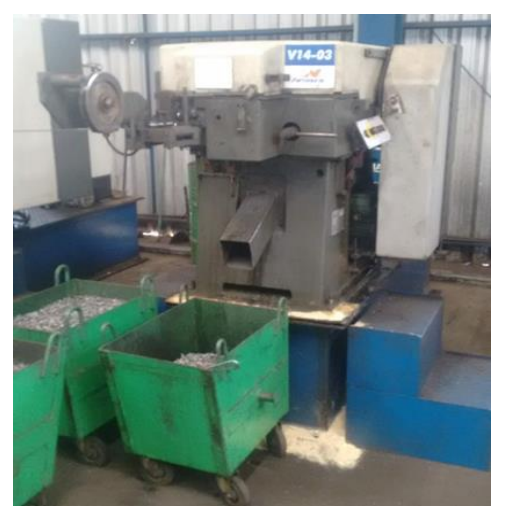

Figura 2: Máquina Vitari modelo V14-R utilizada na fabricação de pregos comuns com cabeça.

A avaliação foi realizada durante a produção do prego $1 \times 1 / 4 \times 13$ (polegada $\times$ BWG) que é fabricado a partir de um arame de aço SAE $1015 \mathrm{Cr}$ trefilado, com diâmetro de 2,41 mm, limite médio de resistência de $98 \mathrm{Kgf} / \mathrm{mm}^{2}$ (961 MPa) e limite de escoamento de $93 \mathrm{Kgf} / \mathrm{mm}^{2}$ (912 MPa).

No processo de produção, o arame é disposto em um carretel rotativo que fica localizado em frente a máquina. $\mathrm{O}$ arame passa por um conjunto de roldanas de endireitamento sendo puxado por um conjunto móvel acionado por uma biela, no qual contém um "puxador" de metal duro. O arame entra no conjunto de corte e conformação. Um par de mordentes fixa o arame e um punção conforma a cabeça do prego ao mesmo tempo em que um par de navalhas realiza o corte da ponta. Os pregos são coletados por um "vagonete" de aço e colocados em uma máquina de polimento. Após o polimento, os pregos são levados para a empacotadeira automática e em seguida embalados.

Visando garantir a qualidade do produto e evitar perdas produtivas, a avaliação visual do prego é realizada no máximo a cada 10 minutos. Nessa avaliação, verifica-se a qualidade do corte da ponta, o formato e a impressão da cabeça. Nesse sentido, a avaliação se baseou em quantificar a produtividade, em kg, ocorrida entre o início de uso da ferramenta e o momento em que fosse possível observar a deformação na região de impressão da cabeça do prego, a qual ocorre após o desgaste dos frisos de contato com o arame, indicando que a vida útil da ferramenta chegou ao fim. 
O custo de produção foi determinado com base no preço de aquisição das ferramentas de cada aço conforme mostrado na Tabela 2 . O custo da nitretação foi de $\mathrm{R} \$ 35,00$. Esse foi o valor orçado com o fornecedor para nitretação a plasma de no mínimo 15 ferramentas, reproduzindo as mesmas condições realizadas nesse estudo. O custo de produção é igual ao preço da ferramenta com ou sem nitretação, dividido pela produção total em toneladas obtida com a ferramenta, obtendo-se o custo em R $\$$ /tonelada. Para a análise de viabilidade utilizou-se como parâmetro de partida o custo obtido com a ferramenta de aço M2 termicamente tratada utilizada pela empresa. Com base no centro de custo disponibilizado pela empresa foi determinado o percentual de redução sobre o custo com a conformação e sobre o custo total de produção.

\section{RESULTADOS}

\subsection{Microscopia eletrônica de varredura}

Os perfis das amostras de aço D2 e M2 submetidas a diferentes tratamentos podem ser observados na Figura 3 de (a) à (d).

As imagens obtidas por microscopia eletrônica de varredura das amostras observadas em (a) e (b) correspondem a nitretação convencional e (c) e (d) realizadas com utilização de gaiola catódica. As nitretações foram todas realizadas em uma temperatura de $480^{\circ} \mathrm{C}$.

Conformes imagens a e c da Figura 3, é possível observar que as amostras de aço D2 nitretadas com a técnica de nitretação convencional e em gaiola apresentaram camada de compostos (CC) de cerca 3 de $12 \mu \mathrm{m}$ respectivamente. $\mathrm{O}$ mesmo ocorreu com aço $\mathrm{M} 2$ que apresentou médias de 0,6 $\mu \mathrm{m}$ para nitretação a plasma convencional e $15,8 \mu \mathrm{m}$ para nitretação em gaiola.
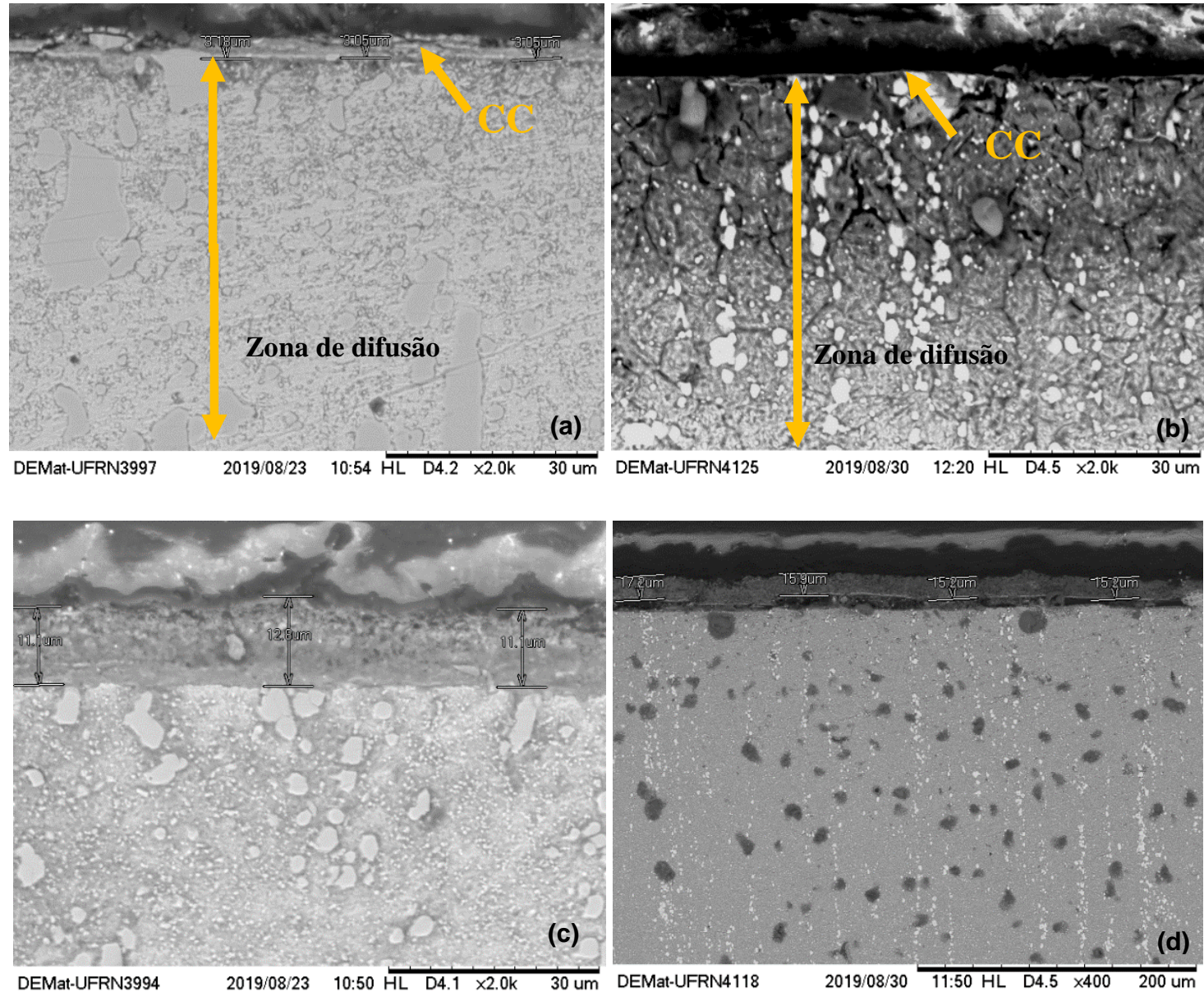

Figura 3: Micrografias por MEV do perfil das amostras submetidas a nitretação a $480^{\circ} \mathrm{C}$, por 3 horas no aço $\mathrm{D} 2$ e 4 horas no aço M2. (a) Nitretação convencional do aço D2, (b) Nitretação convencional do aço M2, (c) Nitretação em gaiola do aço D2, (d) Nitretação em gaiola do aço M2. 

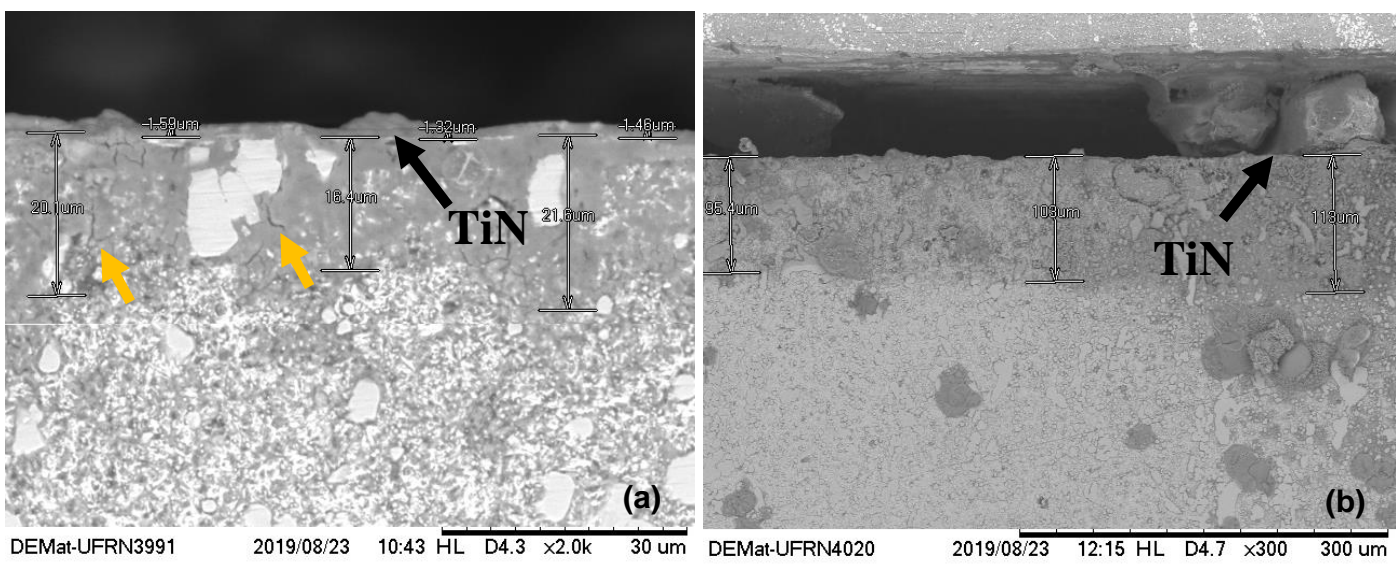

Figura 4: Micrografias por MEV do perfil das amostras com deposição de nitreto de titânio a $420^{\circ} \mathrm{C}$, por 3 horas. (a) aço D2, (b) aço M2.

Amostras nitretadas em gaiola, submetida ao tratamento duplex com deposição de TiN realizada a $420^{\circ} \mathrm{C}$ por 3 horas, são mostradas na Figura 4. Para os dois aços, pode ser observado um fino filme depositado sobre a camada nitretada. Foi encontrado um filme de 1,4 $\mu \mathrm{m}$ na amostra de aço D2 e 1,6 $\mu \mathrm{m}$ na amostra M2, o que é condizente com as espessuras médias citadas na literatura [20]. As zonas de nitretação observadas são maiores após a deposição do TiN. Logo abaixo do filme de TiN, fraturas intergranulares foram observadas na camada nitretação da amostra de aço D2.

\subsection{Difração de Raios-X}

A figura 5 mostra os padrões de difração de Raios-X de amostras de aço AISI D2 e M2 sem nitretação, com nitretação a plasma convencional e nitretação em gaiola catódica, realizadas a $480^{\circ} \mathrm{C}$.
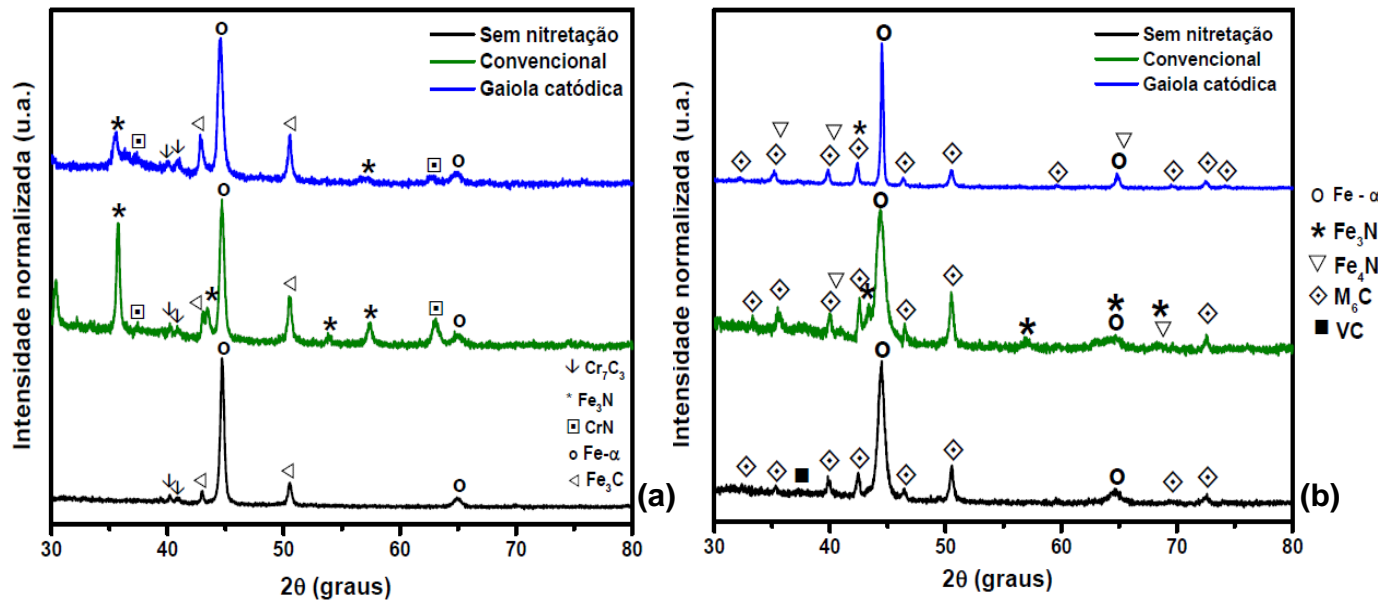

Figura 5: Difração de raios- $X$ das amostras sem nitretação, nitretadas a plasma convencional e em gaiola catódica. (a) aço AISI D2 nitretado a $480{ }^{\circ} \mathrm{C}$, por 3 horas. (b) aço AISI M2 nitretado a $480{ }^{\circ} \mathrm{C}$, por 4 horas

No material de base (Figura 5-a), picos relacionados às fases de ferro alfa ( $\alpha$-Fe) e carboneto de cromo (Cr7C3) foram observados na superfície, representando as principais fases do aço D2 [21]. Os resultados mostraram presença das fases $\mathrm{Fe}_{3} \mathrm{~N}$ e $\mathrm{CrN}$ para os dois métodos de tratamento, sugerindo a formação de uma camada de compostos.

A presença do carboneto $\mathrm{Cr}_{7} \mathrm{C}_{3}$ nos dois tipos de tratamentos conduzidos por $3 \mathrm{~h}$ a $480^{\circ} \mathrm{C}$ evidencia que não houve a dissolução total desses carbonetos para o tempo de tratamento.

A difração das amostras de aço AISI M2 não nitretadas apresentou picos de $\mathrm{M}_{6} \mathrm{C}, \mathrm{VC}$ e martensita $(\alpha$ $\mathrm{Fe}$ ), que são típicos desse aço no estado temperado e revenido [22]. Nas amostras nitretadas, foi possível 
identificar a formação dos nitretos do tipo $\mathrm{Fe}_{3} \mathrm{~N}$ e $\mathrm{Fe}_{4} \mathrm{~N}$, responsáveis pela formação da camada de compostos, o aumento da dureza e do nível de desgaste na superfície nitretada [23; 24].

Os padrões de difração de Raios-X da Figura 6 apresentam os resultados obtidos na análise das amostras de aço AISI D2 e M2 com deposição de nitreto de titânio, previamente nitretadas em gaiola catódica.
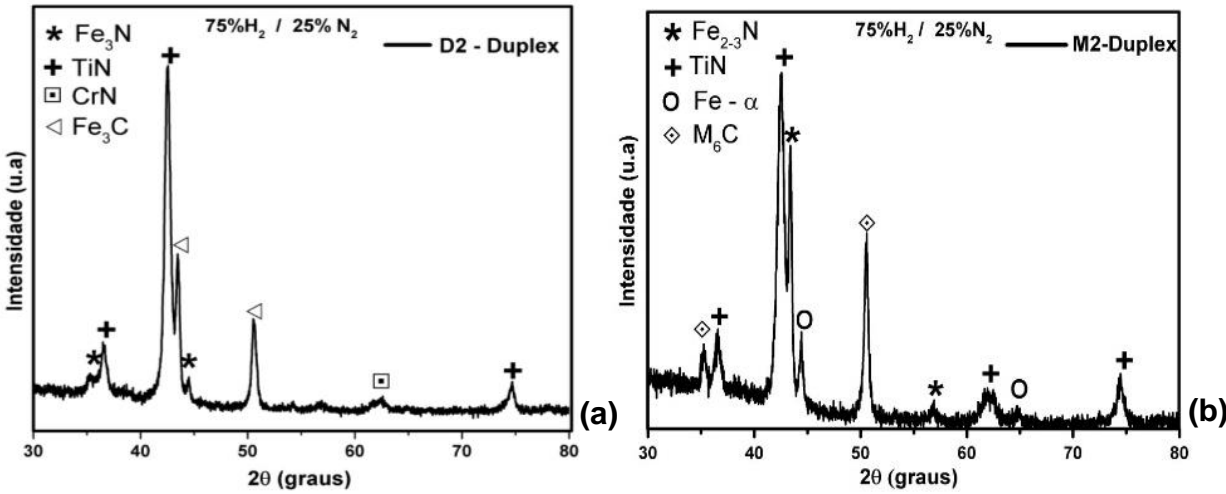

Figura 6: Difração de raios-X dos filmes obtidos por deposição de $\mathrm{TiN}$ a $420^{\circ} \mathrm{C}$ por $3 \mathrm{~h}$ em amostras nitretadas. a) D2 previamente nitretado em gaiola catódica, a $480^{\circ} \mathrm{C}$ por $3 \mathrm{~h}$. b) $\mathrm{M} 2$ previamente nitretado em gaiola catódica, a $480^{\circ} \mathrm{C}$ por 4h.

Os intensos picos identificados para as duas amostras evidenciam a formação do filme de TiN, responsável pela sua elevada dureza, sendo uma das principais característica desse tipo de revestimento [17]. Fases detectadas como $\mathrm{CrN}$ e $\mathrm{Fe}_{3} \mathrm{~N}$ contidas na camada nitretada demonstram a fina espessura do revestimento.

\subsection{Microdureza das amostras}

A Figura 7 apresenta os perfis de microdureza das amostras de aços M2 e D2 nitretadas a plasma convencional e com utilização de gaiola catódica. A microdureza foi medida na secção transversal da amostra e evidencia a profundidade da camada nitretada, onde foram observados aumentos de microdureza até cerca de $90 \mu \mathrm{m}$ de profundidade para o aço D2 quando utilizadas as duas técnicas, com maior dispersão dos resultados para a amostra com nitretação convencional, já a profundidade de endurecimento da camada da amostra de aço M2 com nitretação convencional, alcançou cerca de $150 \mu \mathrm{m}$.
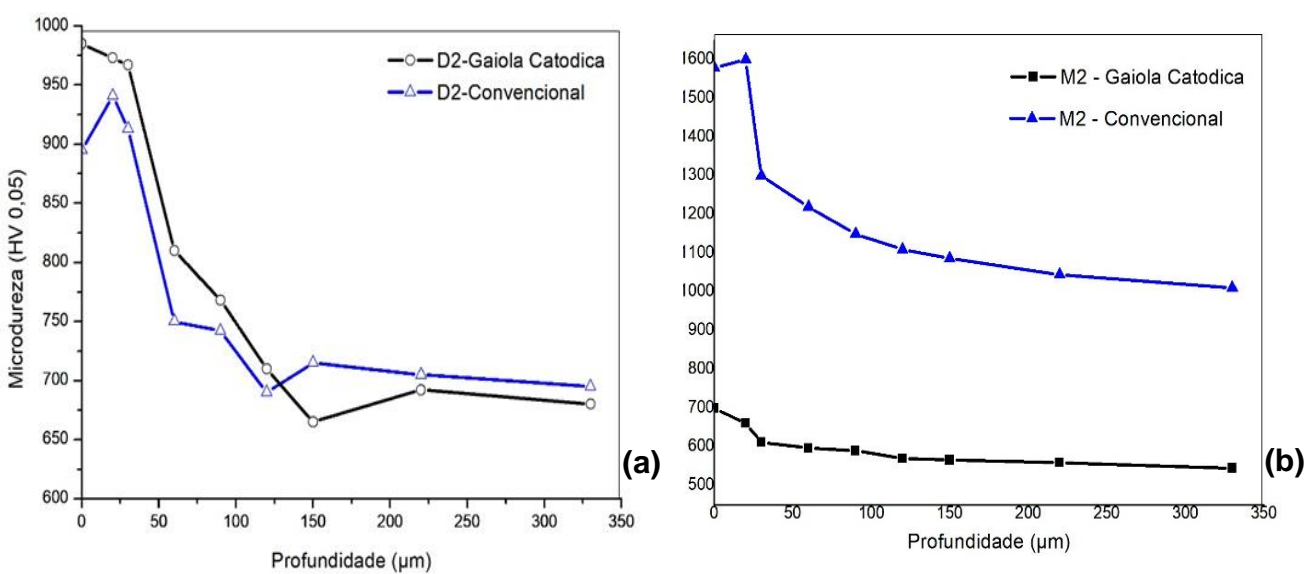

Figura 7: Perfil de microdureza das amostras nitretadas com diferentes técnicas, a $480^{\circ} \mathrm{C}$ : a) D2 nitretado por 3 horas e b) M2 nitretado por 4 horas.

A nitretação do aço M2 realizada em gaiola catódica apresentou um resultado inesperado, considerando que a dureza da camada nitretada iniciou-se com valores inferiores a microdureza do substrato termica- 
mente tratado e caiu para valores inferiores a $550 \mathrm{HV}$.

O perfil de microdureza observado na Figura 8 mostra o comportamento das amostras submetidas ao tratamento duplex. A profundidade da camada endurecida, no aço M2, chegou a cerca de $100 \mu \mathrm{m}$ conforme perfil de microdureza, levando em conta, a redução da microdureza do substrato original de $984 \mathrm{HV}$ para cerca $730 \mathrm{HV}$, conforme observado na profundidade de $500 \mu \mathrm{m}$.

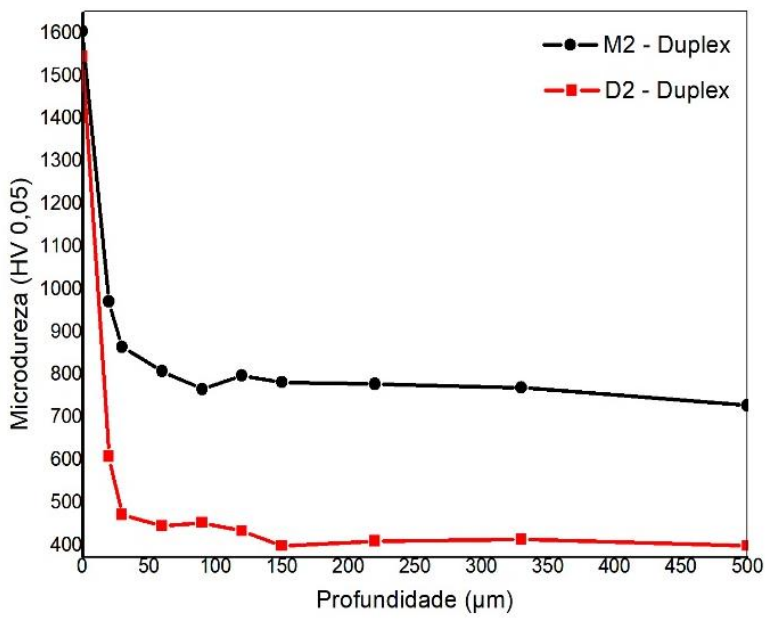

Figura 8: Perfil de microdureza das amostras de aços D2 e M2, com deposição de TiN, a $420^{\circ} \mathrm{C}$, sobre amostras nitretadas em gaiola catódica.

A amostra de aço D2 apresentou resultados inferiores ao previsto, para região de difusão e substrato, após a deposição de nitreto de titânio. Foi observada uma redução para valores abaixo de 500HV a partir de uma profundidade de $30 \mu \mathrm{m}$.

A Tabela 4 apresenta os resultados de microdureza Vickers da superfície das amostras em função do tipo de tratamento aplicado. As espessuras de camada nitretada obtidas por perfil de microdureza e a camada de compostos/deposição de TiN também são exibidas.

Tabela 4: Microdurezas superficiais, profundidade da camada nitretada e da camada de compostos.

\begin{tabular}{c|c|c|c}
\hline CódIGO & $\begin{array}{c}\text { MICRODUREZA } \\
(\mathbf{0 , 0 5} \mathrm{HV}) / \text { DESVIO PADRÃO }\end{array}$ & $\begin{array}{c}\text { ESPESURRA DA CAMA- } \\
\text { DA TOTAL }(\boldsymbol{\mu M})\end{array}$ & $\begin{array}{c}\text { ESPESURRA DA CAMADA DE } \\
\text { COMPOSTOS }(\boldsymbol{\mu M})\end{array}$ \\
\hline M2C & $1524,3 \pm 264$ & 150 & $0,63 \pm 0,23$ \\
\hline D2C & $804,22 \pm 65$ & 90 & $2,9 \pm 0,67$ \\
\hline M2G & $712,0 \pm 26$ & 60 & $15,8 \pm 0,96$ \\
\hline D2G & $922,57 \pm 49$ & 90 & $11,7 \pm 0,98$ \\
\hline M2D & $1607,6 \pm 318$ & 100 & $1,6 \pm 0,48$ \\
\hline D2D & $1546,5 \pm 218$ & 120 & $1,4 \pm 0,18$ \\
\hline
\end{tabular}

Com base nos resultados observados na Tabela 4, houve aumento de microdureza para todos os tratamentos realizados, exceto para amostra M2 tratada em gaiola catódica que exibiu uma redução da microdureza superficial.

A microdureza média da amostra de aço D2 nitretada com o uso de gaiola aumentou em 39,5\% quando comparado com $661,46 \mathrm{HV}$ da amostra apenas temperada e revenida. O aço M2 chegou a 1524,3 HV para a nitretação convencional, um aumento de $54,8 \%$.

Os melhores resultados foram verificados no tratamento duplex, com 1607,6HV para amostra de aço M2, um acréscimo de $63,2 \%$ e $1546,5 \mathrm{HV}$ para o aço D2, que aumentou em $133 \%$, o que indica a efetividade da formação da camada de compostos de TiN.

\subsection{Avaliação de desempenho}

A figura 9 mostra a produtividade, em Kg, das ferramentas submetidas ao teste de desempenho. As ferramen- 
tas de códigos M2T e D2T conforme recebidas (Termicamente tratadas com têmpera e revenimento) foram inicialmente testadas. A ferramenta confeccionada em aço M2 atualmente utilizada na fábrica, produziu $6700 \mathrm{~kg}, 71,1 \%$ a mais do que a ferramenta de aço D2 adquirida exclusivamente para elaboração deste trabalho.

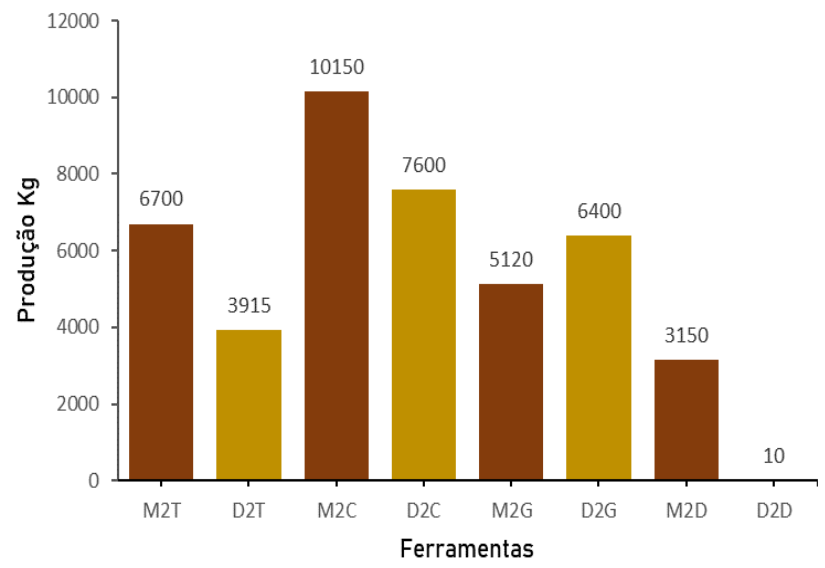

Figura 9: Gráfico de produtividade em kg das ferramentas.

As ferramentas tratadas com a técnica de nitretação convencional apresentaram os melhores resultados, obtendo uma produtividade 51,5\% maior para o aço M2 e 94,2\% para o aço D2, em relação as ferramentas de partida. A nitretação em gaiola catódica proporcionou um ganho de 63,5\% em produtividade para a ferramenta D2G, porém a M2G apresentou produtividade inferior à ferramenta não nitretada.

Com o tratamento duplex, foi obtida uma produtividade de $3150 \mathrm{Kg}$ utilizando a ferramenta de aço M2, a qual corresponde a apenas $47 \%$ da produção obtida com o uso da ferramenta D2T. Não houve produtividade considerável durante o teste da ferramenta de aço D2 com deposição de nitreto de titânio.

Para determinar o custo de produção das ferramentas testadas, considerou-se o preço da nitretação definido pelo fornecedor de ferramentas da empresa. A Tabela 5 mostra o custo de produção por tonelada para cada ferramenta submetida ao teste de desempenho. O custo atual de produção é de $\mathrm{R} \$ 44,03$, considerando a ferramenta confeccionada em aço AISI M2 termicamente tratada.

Tabela 5: Custo de produção

\begin{tabular}{c|c|l|c|c}
\hline AMOSTRA & AÇO AISI & CUSTO DE AQUISIÇÃO & CUSTO DA NITRETAÇÃO & CUSTO/TONELADA (R\$) \\
\hline M2T & $\mathrm{M} 2$ & $\mathrm{R} \$ 295,00$ & $\mathrm{R} \$ 0,00$ & $\mathrm{R} \$ 44,03$ \\
\hline $\mathrm{D} 2 \mathrm{~T}$ & $\mathrm{D} 2$ & $\mathrm{R} \$ 220,00$ & $\mathrm{R} \$ 0,00$ & $\mathrm{R} \$ 56,19$ \\
\hline $\mathrm{M} 2 \mathrm{C}$ & $\mathrm{M} 2$ & $\mathrm{R} \$ 295,00$ & $\mathrm{R} \$ 35,00$ & $\mathrm{R} \$ 32,51$ \\
\hline $\mathrm{D} 2 \mathrm{C}$ & $\mathrm{D} 2$ & $\mathrm{R} \$ 220,00$ & $\mathrm{R} \$ 35,00$ & $\mathrm{R} \$ 33,55$ \\
\hline $\mathrm{M} 2 \mathrm{G}$ & $\mathrm{M} 2$ & $\mathrm{R} \$ 295,00$ & $\mathrm{R} \$ 35,00$ & $\mathrm{R} \$ 64,45$ \\
\hline $\mathrm{D} 2 \mathrm{G}$ & $\mathrm{D} 2$ & $\mathrm{R} \$ 220,00$ & $\mathrm{R} \$ 35,00$ & $\mathrm{R} \$ 39,84$ \\
\hline $\mathrm{M} 2 \mathrm{D}$ & $\mathrm{M} 2$ & $\mathrm{R} \$ 295,00$ & $\mathrm{R} \$ 35,00$ & $\mathrm{R} \$ 104,76$ \\
\hline $\mathrm{D} 2 \mathrm{D}$ & $\mathrm{D} 2$ & $\mathrm{R} \$ 220,00$ & $\mathrm{R} \$ 35,00$ & -- \\
\hline
\end{tabular}

\section{DISCUSSÃO}

Conformes imagens c e d da Figura 3é possível observar que as amostras tratadas em gaiola catódica apresentaram espessuras de camada de compostos (CC) consideravelmente superior aquelas encontradas na nitretação convencional, confirmando o efeito de deposição e a ausência do sputtering ativo na superfície das amostras que compete com a difusão durante a nitretação convencional [12], destacando-se também, a uniformidade da camada de compostos das amostras tratadas por nitretação em gaiola. A amostra de M2 nitretada em gaiola apesentou uma camada com aspecto poroso e diferente da camada densa formada nas outras amostras, conforme observado na figura 3-d. A presença de uma faixa contínua entre o substrato e a camada, como se localizasse em outro plano, foi detectada, portanto a hipótese de que houve um possível desprendi- 
mento de massa dessa região durante a preparação da amostra devido à baixa resistência mecânica da faixa ou o desplacamento da camada de baixa adesão é conveniente.

As fraturas intergranulares observadas na camada de nitretação logo abaixo do filme de TiN da amostra de aço D2, conforme mostra a Figura 4-a, pode ter ocorrido durante a preparação da amostra e é provável que houve precipitação de carbonetos e/ou nitretos em contornos de grãos, o que contribui para fragilização desses contornos, reduzindo dessa forma, a possibilidade do sucesso do filme aplicado [25].

A presença do carboneto $\mathrm{Cr}_{7} \mathrm{C}_{3}$ nos dois tipos de tratamentos conduzidos por $3 \mathrm{~h}$ a $480^{\circ} \mathrm{C}$ conforme observada na Figura 5-a, evidencia que não houve a dissolução total desses carbonetos para o tempo de tratamento, conforme relatado por SOUSA, et al [14], porém observa-se que as intensidades desses picos de carbonetos são menores para o tratamento com maior quantidade e/ou intensidade dos picos relacionados ao $\varepsilon$ $\mathrm{Fe}_{3} \mathrm{~N}$ e CrN, demostrando que a formação de parte dos nitretos ocorre às custas da dissolução dos carbonetos [26]. Não foi evidenciada a presença de $\gamma^{\prime}-\mathrm{Fe}_{4} \mathrm{~N}$ no difratograma do aço $\mathrm{D} 2$, isso pode estar relacionado ao fato de que uma maior quantidade de carbono no aço estabiliza da fase $\mathcal{E}-\mathrm{Fe}_{3} \mathrm{~N}$ e demostra que a fase $\gamma^{\prime}-\mathrm{Fe}_{4} \mathrm{~N}$ é mais facilmente obtida para maiores temperaturas [27] e tempos de tratamento [7].

Para os dois tratamentos no aço M2, foi possível identificar a formação dos nitretos do tipo $\varepsilon-\mathrm{Fe}_{3} \mathrm{~N}$ e $\gamma^{\prime}$ $\mathrm{Fe}_{4} \mathrm{~N}$ (Figura 5-b), responsáveis pelo aumento da dureza e do nível de desgaste de superfícies nitretadas [23, 24]. Houve a redução da quantidade dos picos de $\mathrm{M}_{6} \mathrm{C}$, porém a forte presença desses carbonetos demonstra a formação de uma fina e/ou descontinua camada de compostos. As fases $\mathcal{E}-\mathrm{Fe}_{3} \mathrm{~N}$ e $\gamma$ ' $-\mathrm{Fe}_{4} \mathrm{~N}$ detectadas na amostra nitretada em gaiola catódica não corroboram com a redução superficial de dureza observada na Figura 7-b. Isso pode estar relacionado a técnica de microdureza utilizada para medição da superfície, considerando o aspecto da amostra nitretada em gaiola que dificulta na realização das medições.

A presença do $\mathrm{Fe}_{3} \mathrm{C}$ no tratamento duplex do aço D2 evidenciado na Figura 6-a, confirma a possibilidade da presença desse tipo de carboneto como precipitados em contornos de grãos, o que pode explicar as faturas intergranulares observadas na Figura 4-a.

Analisando-se o perfil de microdurezada da amostra de aço D2, conforme visto na Figura 8, pode ser observado que o amolecimento do substrato se acentuou durante a deposição de TiN, provavelmente devido ao prolongamento do tempo de tratamento e/ou o superaquecimento das amostras a temperaturas superiores à medida. Já o menor efeito sobre o substrato do aço M2 pode ser atribuído a uma maior quantidade de molibidenio que reduz o tamanho do grão da matensita e é um forte formador de carbonetos estáveis e resistentes ao calor $[24,28]$. As reduções na microdureza dos substratos em cerca de $26 \%$ para o M2 e 39\% para o D2 precisam ser melhor investigadas.

Comparando-se os dois aços em relação a mesma técnica, observa-se que na nitretação a plasma convencional, o aço D2 aparentou camada de compostos mais espessa, conforme Tabela 4, já o aço M2 exibe uma zona de difusão que se estende até cerca de $150 \mu \mathrm{m}$ de profundidade, o que pôde ser confirmado a partir do perfil de microdureza. Esse fenômeno pode ser explicado da seguinte forma: a profundidade da zona de difusão é dependente do tempo de tratamento [29], quanto maior o teor de carbono (superior no aço D2), maior será a camada de compostos ocasionada pela formação da fase $\varepsilon$, que possui maior faixa de solubilidade em comparação a fase $\gamma^{\prime}$ e se transforma em carbonitreto de ferro [30,31]; a partir de uma determinada quantidade, o carbono dificulta a difusão do nitrogênio durante a dissolução de carbonetos no estágio de formação de carbonitretos contribuindo para diminuição da zona de difusão e aumento da camada de compostos [31]; o cromo com percentual mais elevado no aço D2 é um forte formador de nitreto, essa reação dificulta a difusão do nitrogênio para maiores profundidades [32].

Na nitretação em gaiola catódica das amostras conforme visto na Figura 3, não foi possível evidenciar a zona de difusão, porém o contrário do que ocorreu na nitretação convencional, a camada de compostos foi superior para o aço M2 (Figura 3-d). Nessa técnica, além da difusão, a deposição por sputtering da superfície do cátodo oco nos furos da gaiola é um fator muito influente, aliado ao fato de que em geral a camada cresce proporcionalmente a raiz quadrada do tempo [23]. Nesse caso, acredita-se que a influência do tempo foi o fator determinante para a maior espessura da camada de compostos do aço M2.

A microdureza das amostras nitretadas em gaiola catódica apresentaram menor desvio padrão. Isso pode ser atribuído a melhor uniformidade e menor rugosidade da camada, o que comprova que não há bombardeamento iônico diretamente na superfície da amostra nitretada em gaiola catódica [14, 33].

A ferramenta de aço M2 que recebeu uma camada de nitretação realizada de forma convencional, alcançou uma produção de $10150 \mathrm{Kg}$, representando uma melhora de 51,5\% em seu desempenho, principalmente devido ao aumento da microdureza superficial e excelente profundidade da zona de difusão. A ferramenta M2 nitretada em gaiola catódica teve sua produtividade comprometida, chegando a reduzir o desempenho em $24 \%$ em relação a ferramenta de partida. Esse fato pode ser explicado pela redução da microdureza superfici- 
al e o amolecimento do substrato após a nitretação, conforme observado no gráfico de perfil de microdureza.

Com os tratamentos duplex obteve-se resultados completamente diferentes com os testes dos dois aços. A ferramneta de aço M2 produzi apenas $3150 \mathrm{Kg}$, o que corresponde a apenas $47 \%$ da produção obtida com ferramenta sem tratamento superficial. $\mathrm{O}$ resultado obtido está relacionado fraca adesão entre o filme de TiN e a camada nitretada, principalmente devido a formação de uma camada de compostos obtida durante a nitretação em gaiola catódica, conforme comprova a difração de Raios-X da Figura 6-b. Na camada de compostos ocorre transformações de fases durante o pré-sputtering no PVD comprometendo as propriedades mecânicas na interface $[8,16,34,35,36]$. A produtividade foi consideravelmente comprometia quando comparada à obtida pela ferramenta apenas nitretada em gaiola catódica (com menor microdureza da superfície e do substrato), o que sugere que o lascamento do filme de alta dureza pode ter potencializado desgaste abrasivo, contribuindo para um pior desempenho dessa ferramenta.

$\mathrm{O}$ aumento absoluto de microdureza no aço M2 nitretado de forma convencional foi 2 vezes superior ao do aço D2. Quanto aos tratamentos duplex, os resultados semelhantes e incrementos totalmente diferentes em relação ao pré-tratamento de nitretação, demonstram que a microdureza do filme de TiN depositado nas mesmas condições, independe da microdureza da superfície nitretada.

A ferramenta de aço AISI D2 tratada com gaiola catódica produziu $2485 \mathrm{Kg}$ a mais do que a ferramenta de partida, representando um ganho de $63,5 \%$ em produtividade, enquanto que a ferramenta com a aplicação da nitretação convencional proporcionou um ganho $94,2 \%$. O fato mostra que uma fina camada de compostos, como é o caso da ferramenta com nitretação convencional já é adequada para a redução do desgaste adesivo, principalmente para ferramentas onde existe impacto [37].

Os resultados dos testes de desempenho mostraram que foi possível reduzir em cerca de $26 \%$ o custo atual de produção com a utilização da ferramenta de aço M2 e em 23,5\% utilizando a ferramenta de aço D2, ambas submetidas a nitretação a plasma convencional. Com a ferramenta de aço D2 nitretada em gaiola, obteve-se uma redução de $9,5 \%$.

As ferramentas de aço M2 nitretada em gaiola e M2 submetida ao duplex registraram aumento do custo de produção devido seus baixos desempenhos. Não foi plausível quantificar o custo de produção da ferramenta de aço D2 com aplicação do duplex.

As paradas para troca da ferramenta não foram levadas em consideração, já que, esse tipo de ferramenta dispõe de um tempo de set-up muito baixo e não afeta de forma significativa a produtividade da máquina.

\section{CONCLUSÕES}

Apesar do menor preço da ferramenta e excelente resistência ao desgaste quando aplicado em rolos, roletes e guias para laminação de arames, o uso do aço AISI D2 (termicamente tratado) para essa aplicação, foi pouco eficiente comparado ao aço AISI M2 atualmente utilizado pela empresa.

Os resultados obtidos evidenciaram que a aplicação da nitretação a plasma convencional e em gaiola catódica, a $480^{\circ} \mathrm{C}$, são efetivas para aumento da vida útil das ferramentas de estampagem e conformação de pregos devido à redução do desgaste adesivo e abrasivo, ocasionada pela formação de nitretos do tipo $\varepsilon-\mathrm{Fe}_{3} \mathrm{~N}$ e $\gamma^{\prime}-\mathrm{Fe}_{4} \mathrm{~N}$ e o consequente aumento da microdureza superficial.

As menores espessuras de camadas foram mais eficientes para a aplicação proposta, devido a menor susceptibilidade a fratura com impacto sobre a ferramenta durante a conformação dos pregos.

O controle da temperatura do processo sobre as ferramentas deve ser tratado de forma cuidadosa para evitar a redução acentuada da dureza do substrato e sua capacidade de carregamento, assim como ocorreu com as amostras M2G e D2D.

$\mathrm{O}$ tratamento duplex apresentou as maiores microdurezas superficiais, porém a baixa produtividade das ferramentas comprova que a aplicação do tratamento nas condições propostas não é uma boa opção para ferramentas de conformação, devida a fraca adesão do revestimento sobre uma espessa camada de compostos obtida por nitretação em gaiola catódica.

A melhor resposta ao tratamento de superfície foi obtida para o aço AISI D2 com aplicação da nitretação convencional, que chegou a um aumento de $94,2 \%$ na produtividade da ferramenta nitretada em relação a ferramenta de termicamente tratada.

A aplicação da nitretação a plasma se mostrou viável na redução do custo atual de produção para os dois aços testados, sendo que o melhor custo-benefício foi conseguido com a nitretação convencional na ferramenta de aço AISI M2 a $480^{\circ} \mathrm{C}$ por $4 \mathrm{~h}$, chegando a uma redução de $26 \%$ no custo de produção com essa 
ferramenta e cerca 3,5\% sobre o custo total de produção o que fornece uma projeção, sobre as 2160 toneladas em volume anual de produção de pregos da fábrica, de uma economia de R \$24.900,00/ano apenas para esse tipo de ferramenta.

\section{AGRADECIMENTOS}

Agradecimento a empresa Ferronorte Industrial por ceder sua estrutura para o desenvolvimento dos testes de desempenho das ferramentas.

\section{BIBLIOGRAFIA}

[1] PINEDO, C.E, "Revestimento PVD e nitretação sob plasma aplicados em ferramentas para conformação e corte a frio," Encontro ABM, 2011; Encontro da Cadeia Ferram. Moldes e Matrizes, 9, n. 1984-9893, pp. 99-108, 2011.

[2] BOURITHIS, L., PAPADIMITRIOU, G.D., SIDERIS, J., "Comparison of wear properties of tool steels AISI D2 and O1 with the same hardness," Tribol. Int., v. 39, pp. 479-489, 2006.

[3] ARAÚJO, A.G.F., "Influéncia da Temperatura na Nitretação Iônica Aplicada a Ferramentas de Corte de Aço AISI M2,” Dissertação de M.Sc., Universidade Federal do Piauí, 2015.

[4] CARDOSO, G.D.S., DIAS, V.W., ROCHA, A.D.S, "Os efeitos do processo de corte cisalhante em barras oriundas do processo de trefilação combinada,” Revista Matéria, v. 22, n. 03, 2017.

[5] DAVIS, J.R. Surface engineering for corrosion and wear resistance. $1^{\mathrm{a}}$ ed. ASM International, 2001.

[6] BALLES, A.C. et al., "Nitretação a Plasma Como Meio Alternativo ou Complementar à Oxidação Negra na Proteção à Corrosão do Aço de Baixo Teor de Carbono," Revista Matériaria, v. 9, n. 4, pp. 360-369, 2004.

[7] DEVI, M.U., MOHANTY, O.N., "Plasma-nitriding of tool steels for combined percussive impact and rolling fatigue wear applications," v. 107, pp. 55-64, 1998.

[8] LEE, I., PARK, Y.-H., PARK, I., "The Characteristics of Surface Layers Produced on SKD 61 Steel by Plasma Radical Nitriding Compared with Conventional Plasma Ion Nitriding," Solid State Phenom., v. 118, pp. 155-160, 2006.

[9] DEPIANTI, M. et al., Effect of plasma nitriding potential on tribological behaviour of AISI D2 coldworked tool steel. Wear, v. 317, n. 1-2, pp. 188-193, 2014.

[10] PESSIN, M.A. et al., The effects of plasma nitriding process parameters on the wear characteristics of AISI M2 tool steel. Tribology Letters, v. 8, n. 4, pp. 223-228, 2000.

[11] NAEEM, M. et al., "Novel duplex cathodic cage plasma nitriding of non-alloyed steel using aluminum and austenite steel cathodic cages," J. Alloys Compd., v. 721, pp. 307-311, 2017.

[12] ALVES JR., C. et al., "Use of cathodic cage in plasma nitriding," Surf. Coat. Technol., v. 201, pp. 24502454, 2006.

[13] DE SOUSA, R.R.M. et al., "Cathodic cage plasma deposition of TiN and TiO 2 thin films on silicon substrates,” Am. Vac. Soc., v. 33, n. 4, pp. 041502-1-041502-5, 2015.

[14] SOUSA, R.R.M. et al., Nitretação iônica em gaiola catódica do aço ferramenta tipo AISI D2 para trabalho a frio. Revista Matéria, v. 14, n. 2, p. 861-868, 2009.

[15] ABREU, L.H.P.. Nitretação a Plasma em Gaiola Catódica: Caracterização e Avaliação do Desempenho da Camada Nitretada em Ferramentas de Conformação. Dissertação de Mestrado. Universidade Federal do Piauí, 2018.

[16] ROUSSEAU, A.F. et al., "Microstructural and tribological characterisation of a nitriding/TiAIN PVD coating duplex treatment applied to M2 High Speed Steel tools," Surf. Coatings Technol., v. 272, pp. 403408, 2015.

[17] BASHIR, M.I. et al., "Enhanced surface properties of aluminum by PVD-TiN coating combined with cathodic cage plasma nitriding," Surf. Coatings Technol. j, v. 327, pp. 59-65, 2017.

[18] FRANCO JUNIOR, A.R.; PINEDO, C.E.; TSCHIPTSCHIN, A.P., "Utilização da nitretação sob plasma como pré-tratamento ao revestimento TiN-PVD na geração de superfícies dúplex no aço AISI H13," Tecnol. em Metal. Mater. e Mineração, v. 5, n. 3, pp. 179-185, 2009.

[19] ASTM, C. 1327-08. standard test method for vickers indentation hardness of advanced ceramics. Annual Book of ASTM Standards, 2008. 
[20] CHEN, YING, XUEYUAN NIE, "Study on Fatigue and Wear Behaviors of a TiN Coating Using an Inclined Impact-Sliding Test", Surface \& Coatings Technology, vol. 206, pp. 1977-82, 2011.

[21] CHO, T.K. et al., "Enhanced surface hardening of AISI D2 steel by atomic attrition during ion nitriding," Surf. Coat. Technol., v. 251, pp. 115-121, 2014.

[22] AKBARI, A. et al., "Effect of the initial microstructure on the plasma nitriding behavior of AISI M2 high speed steel," Surf. Coatings Technol., v. 204, n. 24, pp. 4114-4120, 2010.

[23] SOUSA, R.M. et al., "Nitretação em gaiola catódica: influência do tempo de tratamento," Revista Matéria, v. 13, n. 1, pp. 119-124, 2008.

[24] VALES, S.D.S. et al. Effect of low temperature nitriding of $100 \mathrm{Cr} 6$ substrates on TiN coatings deposited by IBAD. Materials Research, v. 18, n. 1, p. 54-58, 2015.

[25] SUN, Y.; BELL, T. Plasma surface engineering of low alloy steel. Materials Science and Engineering, v. 140 , p. $419-434,1991$.

[26] GARZÓN, C.M., FRANCO JR, A.R., TSCHIPTSCHIN, A.P., "Thermodynamic Analysis of M 7 C 3 Carbide Dissolution during Plasma Nitriding of an AISI D2 Tool Steel,”v. 57, pp. 737-745, 2017.

[27] DÍAZ-GUILLÉN, C. et al., "Electrochemical Corrosion Performance of AISI D2 Tool Steel Surface Hardened by Pulsed Plasma Nitriding,” v. 8, pp. 973-982, 2013.

[28] LIEN, T.S. et al. In-service performance of components treated with plasma nitriding and arc ion plating duplex coatings. Journal of Materials Processing Technology, v. 184, n. 1-3, p. 401-406, 2007.

[29] FRANCO JR., A.R.; OSPINA, C.M.G.; TSCHIPTSCHIN, A.P. Análise Numérica e Experimental da Cinética de Nitretação a Plasma de Açõs ferramenta. Revista ABM, v. 1, n. 1, p. 6-11, 2004.

[30] ALVES JR, C. Nitretação a plasma: fundamentos e aplicações. 1a ed. Natal, 2001.

[31] CHO, K.S.; LEE, C., "The Effects of Carbon on lon- Nitriding," J. Eng. Mater. Technol., v. 102, pp. 229-233, 1980.

[32] KOLOZVARY, Z.; PLASMATERM, S.C. Residual Stresses in Nitriding. Handbook of Residual Stress Deformation and of Steel. $1^{\mathrm{a}}$ ed. United States of America: ASM International, 2002.

[33] De Sousa, R.R.M., et al.,"Nitriding of AISI 1020 Steel : Comparison Between Conventional Nitriding and Nitriding with Cathodic Cage," Mater. Res., v. 17, n. 3, n. 1516-1439, pp. 708-713, 2014.

[34] NICKEL, J. et al., "Evaluation of the wear of plasma-nitrided and TiN-coated HSS drills using conventional and Micro-PIXE techniques," Wear, v. 239, n. 2, pp. 155-167, 2000.

[35] FRANCO JUNIOR, A.R.; PINEDO, C.E.; TSCHIPTSCHIN, A.P., "Utilização da nitretação sob plasma como pré-tratamento ao revestimento TiN-PVD na geração de superfícies dúplex no aço AISI H13," Tecnol. em Metal. Mater. e Mineração, v. 5, n. 3, pp. 179-185, 2009.

[36] SERRA, P.L.C., "Aplicação de Nitretação e Tratamento Duplex em Brocas de Aço Rápido - HSS," Dissertação de M.Sc., Universidade Federal do Piauí, 2018.

[37] DAS, K. et al. Microstructure and wear behaviour of pulsed plasma nitrided AISI H13 tool steel. Canadian Metallurgical Quarterly, v. 55, n. 4, p. 402-408, 2016.

\section{ORCID}

Edno da Silveira Costa

Rômulo Ribeiro Magalhães de Sousa

Renan Matos Monção

Maxwell Santana Libório

Thércio Henrique de Carvalho Costa https://orcid.org/0000-0001-6648-0201

https://orcid.org/0000-0003-2062-6505

https://orcid.org/0000-0003-4893-9976

https://orcid.org/0000-0003-1579-8775

https://orcid.org/0000-0001-7429-4273 